\title{
Increasing antimicrobial resistance of Helicobacter pylori infection among Saudi patients undergoing upper gastrointestinal endoscopy
}

\author{
Fahad A.S. Al-Eidan, ${ }^{1,2}$ Mohamed Alnaser, ${ }^{2}$ Sameera M. Aljohani, ${ }^{1,2}$ Mishal Al Johani, ${ }^{2}$ Ahmed El Hafi, ${ }^{2}$ \\ Abdullah Al Jahdaly, ${ }^{2}$ Abdulrahman Al Khurmi ${ }^{2}$ \\ ${ }^{1}$ King Saud bin Abdulaziz University for Health Sciences, Riyadh; ${ }^{2}$ King Abdulaziz Medical City, Riyadh, Saudi Arabia
}

\begin{abstract}
There is growing concern about Helicobacter pylori resistance strains being the main agent contributing to eradication failure. In this study, we evaluated the prevalence and antimicrobial susceptibility trends of $H$. pylori over a period of time. Over a period of seven years a total of 384 biopsy specimens were sent to the microbiology department and evaluated for culturing $H$. pylori and assess its susceptibility. Biopsy specimens that cultured and where bacterial susceptibility was determined were regarded as H. pylori positive, and specimens that failed to culture were considered H. pylori negative. A total of 221 patients with $H$. pylori positive were assessed and antimicrobial susceptibility was determined. The overall prevalence of $H$. pylori infections among Saudis undergoing upper gastrointestinal endoscopy, with indicated specimens, was 57.6\%. Antimicrobial susceptibility was evaluated; overall clarithromycin resistance was found to be $4.5 \%$ and metronidazole resistance $52.5 \%$. The number of clarithromycin resistant strains has increased significantly from $2.5 \%$ in 2008 to $10 \%$ in 2014 ( $\mathrm{P}<0.0001$ ), and metronidazole resistance strains from $47 \%$ in 2008 to $65 \%$ in $2014(\mathrm{P}<0.001)$. H. pylori infection is very common among Saudi patients with peptic ulcer disease. Resistance of $H$. pylori against clarithromycin and metronidazole has increased significantly over the seven-year period. This suggests a need to monitor the annual antimicrobial susceptibility pattern.
\end{abstract}

\section{Introduction}

Helicobacter pylori discovery and the recognition of its clinical impact on peptic ulcer diseases have been considered a major development in clinical practice of medicine. It is a microaerobic, Gram-negative spiral

Correspondence: Fahad A.S. Al-Eidan, College of Medicine, King Saud Bin Abdulaziz University for Health Sciences, King Abdulaziz Medical City, Riyadh, Saudi Arabia.

E-mail: faleidan@gmail.com

Key words: Antimicrobial resistance; endoscopy; Helicobacter pylori; prevalence.

Contributions: FASA-E designed and initiated the study, analyzed the data and drafted the manuscript; MA, SAM, MA-J, AE-H, AA-J and AA-K contributed to the collection and interpretation of the data and revised the manuscript. All authors approved the final version of the manuscript.

Conflict of interest: the authors declare no potential conflict of interest.

Received for publication: 22 October 2016.

Revision received: 9 January 2017.

Accepted for publication: 17 January 2017.

This work is licensed under a Creative Commons Attribution NonCommercial 4.0 License (CC BY-NC 4.0).

(C) Copyright F.A.S. Al-Eidan et al., 2017

Licensee PAGEPress, Italy

Italian Journal of Medicine 2017; 11:318-321

doi:10.4081/itjm.2017.804 bacterium that grows in the stomach of more than half of the world's population. ${ }^{1} \mathrm{H}$. pylori infections are closely associated with a range of peptic diseases such as chronic gastritis, peptic ulcer disease, and linked to the development of gastric cancer. ${ }^{1,2}$ Elimination of the infection definitely improves peptic ulcer disease. Therefore, experts' opinion and international guidelines recommend eradication of $H$. pylori for patients with symptoms. ${ }^{3,4}$ Several treatment regimens are available and widely used with different success rates, mostly consisting of two antimicrobials and one proton pump inhibitor. ${ }^{5,6}$ Failure of therapy is the result of not only non-adherence but also of the resistance of the bacterium to the prescribed antimicrobials. ${ }^{7}$ The presence of resistant strains substantially decreases the success rate of $H$. pylori eradication. ${ }^{8,9}$

The focus of this study is to determine the prevalence of $H$. pylori infection and the antimicrobial susceptibility pattern over a period of time.

\section{Materials and Methods}

All patients undergoing upper gastrointestinal endoscopy in the endoscopy unit at King Abdulaziz Medical City (KAMC), Riyadh, Saudi Arabia, and who satisfied the following inclusion and exclusion criteria, were retrospectively recruited into this study. The study was approved by the ethical committee, King Abdullah International Medical Research Center (KAIMRC). Patients met the following criteria were 
eligible for enrolment: being aged $\geq 18$ years and above with symptoms of dyspepsia, and no previous antimicrobial therapy to eradicate $H$. pylori infection. The following exclusion criteria were applied: previous gastric surgery; any use of bismuth, antimicrobial agents, H2-receptor antagonists, proton pump inhibitors, or sucralfate within four weeks prior to endoscopic examination. The main indications for performing endoscopy are the presence of upper abdominal complaints, anemia, or reflux complaints. One biopsy specimen from the gastric antrum or duodenal ulcer for detection of $H$. pylori was collected during upper endoscopy, when it is clinically indicated. The biopsy specimens were sent immediately and processed at the microbiology department in the KAMC. A selective media (Columbia agar with 7\% horse blood and $H$. pylori selective supplement, Oxoid, Basingstoke, UK) was used to culture $H$. pylori from the biopsy specimens under microaerophilic conditions produced by a gas-generating system (CampyGen, Oxoid, Basingstoke, UK) for three to six days.

\section{Statistical analysis}

A Chi-square test was used to assess the potential association of $H$. pylori infection with the following proportions: age, gender, body mass index, smoking, and peptic ulcers. The risks were estimated using the odds ratios and $95 \%$ confidence interval. A multivariate logistic regression model was used to determine the independent risk factors associated with $\mathrm{H}$. pylori infection. The Cochran-Armitage test for linear trends was applied to analyze an antimicrobial-resistance time trend over a seven-year period, using STATA 12.0 software. All tests were two-sided, and the results were considered significant at a $\mathrm{P}$ value of $<0.05$.

\section{Results}

A total of 384 patients underwent endoscopy where biopsy specimens were obtained and sent to the microbiology department for culturing and processing during the study period (from January 2008 to December 2014). Of the 384 biopsy specimens, 221 were cultured and bacterial susceptibility was successfully identified; these patients served as the H. pylori case group, and $H$. pylori negative patients were used as the control group. The mean age of the case group was 65.4 years $( \pm 16)$ and $129(58.4 \%)$ were female (Table 1). The overall prevalence of $\mathrm{H}$. pylori infection in our study was $57.6 \%$. The prevalence of $H$. pylori among females was higher than in the male population but was not statistically significant $(\mathrm{P}=0.392)$. The prevalence of $H$. pylori infection in patients aged $40-59$ years was significantly higher than in other age groups $(\mathrm{P}=0.021)$. The proportion of $H$. pylori positive cases who were smokers was $37.6 \%$ - statistically significant when compared to the proportion of smokers in the H. pylori negative control group - $20.2 \%(\mathrm{P}<0.001)$. No associa-

Table 1. Demographic characteristics and prevalence of Helicobacter pylori infection.

\begin{tabular}{|c|c|c|c|c|}
\hline Variables & $\begin{array}{l}H . \text { pylori positive } \\
\text { Cases } n=221(\%)\end{array}$ & $\begin{array}{l}H . \text { pylori negative } \\
\text { Control } n=163(\%)\end{array}$ & OR $(95 \% C I)$ & P value \\
\hline \multicolumn{5}{|l|}{ Age (years) } \\
\hline$\leq 3923$ & $(10.4)$ & $28(17.2)$ & 1.00 & 1.000 \\
\hline $40-59$ & $167(75.6)$ & $100(61.3)$ & $2.03(1.11-3.72)$ & 0.021 \\
\hline$\geq 60$ & $31(14.0)$ & $35(21.5)$ & $1.08(0.52-2.25)$ & 0.840 \\
\hline \multicolumn{5}{|l|}{ Gender } \\
\hline Male & $92(41.6)$ & $75(46.0)$ & 1.00 & 1.000 \\
\hline Female & $129(58.4)$ & $88(54.0)$ & $0.84(0.87-1.08)$ & 0.392 \\
\hline \multicolumn{5}{|l|}{ BMI } \\
\hline Underweight (BMI<18.5) & $17(7.7)$ & $10(6.1)$ & 1.00 & 1.000 \\
\hline Healthy (BMI=18.5-24.9) & $70(31.7)$ & $53(32.5)$ & $1.29(0.55-3.04)$ & 0.550 \\
\hline Overweight $(\mathrm{BMI}=25-29.9)$ & $58(26.2)$ & $42(25.8)$ & $1.01(0.65-1.65)$ & 0.975 \\
\hline Obese $(\mathrm{BMI} \geq 30)$ & $76(34.4)$ & $58(35.6)$ & $1.10(0.62-1.78)$ & 0.844 \\
\hline \multicolumn{5}{|l|}{ Smoking } \\
\hline No & $138(62.4)$ & $130(79.8)$ & 1.00 & 1.000 \\
\hline Yes & $83(37.6)$ & $33(20.2)$ & $2.37(1.48-3.79)$ & $<0.001$ \\
\hline \multicolumn{5}{|l|}{ Gastrointestinal diseases } \\
\hline \multicolumn{5}{|l|}{ Peptic ulcer } \\
\hline No & $62(28.1)$ & $119(73.0)$ & 1.00 & 1.000 \\
\hline Yes & $159(71.9)$ & $44(27.0)$ & $6.94(4.41-10.92)$ & $<0.001$ \\
\hline
\end{tabular}

OR, odds ratios; CI, confidence interval; BMI, body mass index. 
tion was observed between the rate of $H$. pylori infection and body mass index categories. H. pylori infection was observed significantly in peptic ulcer patients $(\mathrm{P}<0.001)$.

In the logistic regression model analysis, performed to determine the independent risks, we found a statistical significant correlation between smoking and $H$. pylori infection $(\mathrm{P}<0.001)$; H. pylori infection was also identified as a predominant risk in patients suffering from peptic ulcer disease $(\mathrm{P}<0.001)$ (Table 2).

The overall antimicrobial resistance rates were as follows: amoxicillin $0.9 \%$, tetracycline $1.4 \%$, clarithromycin $4.5 \%$, and metronidazole $52.5 \%$. Table 3 represents the trends of clarithromycin-resistance rates and metronidazole-resistance rates over a seven-year period. The rate of clarithromycin-resistance was significant elevated $(\mathrm{P}<0.0001)$. The rate increased fourfold over the seven-year period.

\section{Discussion and Conclusions}

The overall prevalence of $H$. pylori infection among the Saudi population that underwent endoscopy over the seven-year period was $57.6 \%$. The relatively low prevalence rate of $H$. pylori infection in this study may be attributed to the design of the study in which only patients who had a biopsy taken and sent to laboratory were included in the study. In a preliminary report, a similar prevalence rate of $H$. pylori was found in patients undergoing bariatric surgery. ${ }^{10}$ Age as a risk factor was analyzed and it was found that $H$. pylori infection was higher in the middle-age category than in other age categories. Similarly, Zhu et al. found the same prevalence. ${ }^{11}$ However, several studies have showed that the prevalence of $H$. pylori infections decreased with increased age. ${ }^{12}$ Several studies in the Middle East Countries have reported different prevalence rates of $H$. pylori infections. ${ }^{13,14}$ The contributing factors responsible for these differences may include socioeconomic, geographic, or life style, ethnicity or the location of different population..$^{15,16}$

H. pylori resistance to antimicrobials is attributed to several factors, such as frequent consumption of antimicrobials, misuse of antimicrobials, and lack of control in prescribing and dispensing. In our study, the resistance of $H$. pylori against clarithromycin increased four-fold over the seven-year period, but still remained low with an overall rate of $4.5 \%$, while resistance against metronidazole was reported as $52.5 \%$. However, the rate of clarithromycin resistance in our study is much lower than what has been reported in different regions of Saudi Arabia with resistance percentage of $27.7 \%$ and $21 \%{ }^{17,18}$ Worldwide, a rising trend in the emergence of resistance to clarithromycin, levofloxacin and metronidazole among $H$. pylori strains has been noticed. ${ }^{19,20}$ The phenomenon of antimicrobial resistance is expected to rise with widespread use of antimicrobials for eradication of $H$. pylori infection. ${ }^{21}$ In a recent literature review authors conclude that resistance to clarithromycin and levofloxacin has increased during the last 6 years. ${ }^{20}$ Polish researchers found that the primary resistance to clarithromycin was seen in $19-21 \%$ of the isolates. ${ }^{22}$ Similarly, the resistant rates among Pakistani popula-

Table 2. Logistic multivariate regression analysis of $\mathbf{H e}$ licobacter pylori infection.

\begin{tabular}{lcc}
\hline Variable & OR $(\mathbf{9 5 \%} \mathbf{C I})$ & P value \\
\hline Age & $0.81(0.84-3.31)$ & 0.142 \\
\hline Smoking & $2.42(1.43-4.09)$ & 0.001 \\
\hline Peptic ulcer & $7.01(0.61-0.83)$ & $<0.001$ \\
\hline
\end{tabular}

OR, odds ratios; CI, confidence interval.

Table 3. Antimicrobial resistance rates over a seven-year period.

\begin{tabular}{|c|c|c|}
\hline Year & Clarithromycin-resistance rate $(95 \% \mathrm{CI})$ & Metronidazole-resistance rate $(95 \% \mathrm{CI})$ \\
\hline 2008 & $2.5 \%(0.1-13.9)$ & $47.5 \%(28.0-74.4)$ \\
\hline 2009 & $2.8 \%(0.1-15.5)$ & $52.8 \%(31.8-82.4)$ \\
\hline 2010 & $2.8 \%(0.1-15.5)$ & $47.2 \%(27.5-75.6)$ \\
\hline 2011 & $3.0 \%(0.1-16.9)$ & $48.5 \%(27.7-78.7)$ \\
\hline 2012 & $6.5 \%(0.8-23.3)$ & $54.8 \%(31.9-87.8)$ \\
\hline 2013 & $8.0 \%(1.0-28.9)$ & $60.0 \%(33.6-99.0)$ \\
\hline 2014 & $10.0 \%(1.2-36.1)$ & $65.0 \% 34.6-111.2)$ \\
\hline$P$ value & $<0.0001$ & $<0.001$ \\
\hline Overall & $4.5(2.2-8.3)$ & $52.5(43.4-63.0)$ \\
\hline
\end{tabular}

$\mathrm{CI}$, confidence interval. 
tion were higher: $89 \%$ for metronidazole, $36 \%$ for clarithromycin, $37 \%$ for amoxicillin, $18.5 \%$ for ofloxacin, and $12 \%$ for tetracycline. Furthermore, clarithromycin resistance increased from $32 \%$ in 2005 to $38 \%$ in $2008 .{ }^{23}$ However, researchers from Malaysia reported no resistance against clarithromycin. This was possibly due to the restriction applied to macrolides prescribing in the general practice. ${ }^{24}$ Instead, in most of the countries in which clarithromycin susceptibility has been studied, resistance has risen over time. According to the results of our study, metronidazole should not be used to eradicate $H$. $p y$ lori infections.

Our conclusion is that the resistance of $H$. pylori against clarithromycin and metronidazole has increased significantly over the seven-year period in Saudi Arabia. The use of regimens containing metronidazole in the eradication of $H$. pylori infection should be avoided. Continuous monitoring of antimicrobial susceptibility patterns for $H$. pylori is essential in order to select appropriate agents to achieve higher eradication rates.

\section{References}

1. Shanks AM, EM El-Omar. Helicobacter pylori infection, host genetics and gastric cancer. J Dig Dis 2000; 10:157-64

2. Cambau E, Allerheiligen V, Coulon C, et al. Evaluation of a new test, genotype HelicoDR, for molecular detection of antibiotic resistance in Helicobacter pylori. J Clin Microbiol 2009;7:3600-7.

3. Chey WD, Wong BC. American College of Gastroenterology guideline on the management of Helicobacter pylori infection. Am J Gastroenterol 2007;102:1808-25.

4. O'Connor A, Gisbert J, O'Morain C. Treatment of Helicobacter pylori infection. Helicobacter 2009; 1:46-51.

5. Malfertheiner P, Megraud F, O'Morain C, et al. Concepts in the management of Helicobacter pylori infection. The Maastricht III Consensus Report. Gut 2007;56:772-81.

6. Mana F. The Maastricht III consensus: summary and comments. Acta Gastroenterol. Belg 2009;72:344-9.

7. Al-Eidan FA, McElnay JC, Scott MG, McConnell JB. Management of Helicobacter pylori eradication--the influence of structured counselling and follow-up. Br J Clin Pharmacol 2002; 53:163-71.

8. Mégraud F, Lehours P. Helicobacter pylori detection and antimicrobial susceptibility testing. Clin Microbiol Rev 2007;20:280-322.

9. Megraud FH. pylori antibiotic resistance: prevalence, importance and advantages in testing. Gut 2004; $53: 374-84$
10. Al-Akwaa. Prevalence of Helicobacter pylori infection in a group of morbidly obese Saudi patients undergoing bariatric surgery: a preliminary report. Saudi J Gastroenterol 2010;16:264-7.

11. Zhu Y, Zhou X, Wu J, et al. Risk factors and prevalence of helicobacter pylori infection in persistent High incidence area of gastric carcinoma in Yangzhong city. Gastroenterol Res Pract 2014;2014:481365.

12. Chen S, Ying L, Kong M, et al. The prevalence of Helicobacter pylori infection decreases with older age in atrophic gastritis. Gastroenterol Res Pract 2013;2013.

13. Lim SH, Kwon JW, Kim N, et al. Prevalence and risk factors of Helicobacter pylori infection in Korea: nationwide multicenter study over 13 years. BMC Gastroenterol 2013;13.

14. Alazmi WM, Siddique I, Alateeqi N, Al-Nakib B. Prevalence of Helicobacter pylori infection among new outpatients with dyspepsia in Kuwait. BMC Gastroenterol 2010;10.

15. Bastos J, Peleteiro B, Barros R, et al. Sociodemographic determinants of prevalence and incidence of Helicobacter pylori infection in Portuguese adults. Helicobacter 2013;18:413-22.

16. Pounder RE, Ng D. The prevalence of Helicobacter pylori infection in different countries. Aliment Pharmacol Ther 1995;9:33-9.

17. Momena AM, Asghar AH. Prevalence and antibiotic resistance among helicobacter pylori clinical isolates from main Hospitals in the western region of Saudi Arabia. Pak J Med Sci 2008;1:100-3.

18. Marie MA. Seroprevalence of Helicobacter pylori infection in large series of patients in an urban area of Saudi Arabia. Korean J Gastroenterol 2008;52:226-9.

19. De Francesco V, Giorgio F, Hassan C, et al. Worldwide H. pylori antibiotic resistance: a systematic review. J Gastroint Liver Dis 2010;19:409-14.

20. Ghotaslou R, Leylabadlo HE, Asl YM. Prevalence of antibiotic resistance in Helicobacter pylori: a recent literature review. World J Methodol 2015;5:164-74.

21. Group CHPR. Prevalence of Helicobacter pylori research to antibiotics and its influence on the treatment outcome in China: a multicenter clinical study. Chinese J Gastroenterol 2007;12:525-30.

22. Karczewska E, Klesiewicz K, Skiba I, et al. Variability in prevalence of helicobacter pylori strains resistant to clarithromycin and levofloxacin in southern Poland. Gastroenterol Res Pract 2012;2012.

23. Khan A, Farooqui A, Manzoor H, et al. Antibiotic resistance and cagA gene correlation: a looming crisis of Helicobacter pylori. World J Gastroenterol 2012;18: 2245-52.

24. Goh KL, Navaratnam P. High helicobacter pylori resistance to metronidazole but zero or low resistance to clarithromycin, levofloxacin, and other antibiotics in Malaysia. Helicobacter 2011;16:241-5. 